\title{
Nene Curculioniden aus der Krim und dem Kaukasus, nebst Bemerkungen über einige schon bekannte Arten.
}

Von 0. Retowski in Theodosia (Krim).

I.

\section{Cleonus (Mecaspis) Reitteri n. sp.}

Oblongus, niger, cinereo-albido-tomentosus, subtus albido-pilosus; fronte lata; oculis angustissimis; rostro capite duplo fere longiore, tricarinato, carina media distincta, carinis lateralibus obsoletis apicem versus divergentibus; prothorace subquadrato anterius rotundato-angustato, basi bisinuato, alutaceo punctisque majoribus sparsis immixto, ante scutellum longitudinaliter impresso, lateribus densius tomentosis; scutello longo triangulari demerso; elytris prothoracis basi latioribus, humeris rotundatis, ampliatis, postice angustatis, apice singulatim subacuminatis, supra parum depressis, remote punctato-striatis, strïs basi magis impressis, albidis, plagis obsoletis maculosis, pone basin macula alba obliqua ornatis; abdomine punctis majoribus densis, translucentibus nigris; coxis, femoribus tibiisque intus sat longe pilosis. Long. (sine rostro) $8-12$, lat. $2 \cdot 75-4.5 \mathrm{~mm}$.

Hab. Tauria (Theodosia, Sudak) et Cauc. occid. (Novorossisk).

Schwarz, ziemlich dicht mit weissgrauem Toment fleckig bekleidet. Kopf und Rüssel sehr fein gerunzelt, Scheitel gewölbt, die Stirn ziemlich breit, flach, mit fast immer deutlichem Punkte in der Mitte, Augen sehr schmal, fast mehr als doppelt so lang als breit, zu beiden Seiten weissgelb tomentirt, der Rüssel beinahe doppelt so lang als der Kopf, an der Spitze erweitert, mit deutlichem Mittelkiele, der meist vom Stirnpunkte beginnt und an der Spitze verschwindet, und zwei oft nur angedeuteten Seitenkielen, die nach vorn divergiren. Fühler kurz und kräftig, Schaft so lang wie die ersten sechs Glieder des Fadens, erstes Glied des letzteren etwas länger als breit, an der Spitze verdickt, dicker als die folgenden, das zweite so lang als breit, die übrigen viel breiter als lang, Keule länglich zugespitzt. Halsschild nur wenig kürzer als breit, Seiten wenig gerundet, nach vorn verengt, Basis doppelt ausgerandet mit grösseren Punkten ziemlich dicht besetzt und ausserdem 
mit einem tiefen Längseindrucke vor dem Schildchen, der bisweilen fast bis zur Mitte des Halsschildes reicht. Die Tomentirung des Halsschildes ist auch bei reinen Stücken viel schwächer als die der Flügeldecken; bei frischen Exemplaren bildet dieselbe acht gebogene Längsbinden, von diesen sind die beiden inneren eher als länglich dreieckige, mit den langen Seiten gegen einander gekehrte Flecke zu bezeichnen, die auf den hinteren zwei Dritteln des Halsschildes stehen; diese Flecke werden von einem Paar in der Mitte nach innen eingeknickter Linien eingeschlossen, dann folgt jederseits eine ziemlich gerade nach vorn verkürzte Linie und endlich an jeder Seite des Halsschildes die vierte Binde, die vorn winklig nach unten gebogen ist; diese Seitenlinien sind am deutlichsten erkennbar. Flügeldecken mit ziemlich parallelen Seiten, aber hinten schlank verengt, breiter als der Thorax, mit abgerundeten Schultern, etwa doppelt so lang als breit; jede Decke einzeln zugespitztabgerundet, gestreiftpunktirt, die Punkte an der Basis stärker und weitläufiger. Die Tomentirung ist an vielen Stellen, ausgenommen auf den dicht gelbgrau beschuppten Suturalstreifen, schwächer, so dass die Decken weissscheckig werden, immer jedoch erscheint - auch bei etwas abgeriebenen Exemplaren noch sichtbar - an der Basis jeder Flügeldecke ein dicht beschuppter grosser, weisslicher Fleck, der die Art gut charakterisirt; die Schwiele besitzt oben einen kleinen weissen Fleck und ebenso ist die äusserste Spitze der Flügeldecken stets weiss. - Die ganze Unterseite ist mit zahlreichen, scharfen, schwarzen Nabelpunkten besetzt, die auch auf dem Abdomen ziemlich dicht stehen. Die Hüften, Schenkel und Schienen sind unten mit ziemlich langen, abstehenden Wollhaaren besetzt.

Cleonus Reitteri ist zwischen $\mathrm{Cl}$. barbatus Faust und $\mathrm{Cl}$. 8-signatus Gyll. zu stellen, mit denen er (sowie auch emarginatus F.) die parallele Deckenform gemein hat, während die übrigen Arten der Mecaspis-Gruppe, alternans Ol., caesus Gyll. und coenobita Ol., an den Seiten gerundete Decken besitzen. Von barbatus unterscheiden ihn jedoch namentlich die schmäleren Augen, der längere zur Spitze breitere Rüssel, die verschiedene Zeichnung des Halsschildes und der Flügeldecken und die viel dichteren, scharfen, schwarzen Nabelpunkte auf dem Abdomen. Letztere besitzt in derselben Schärfe auch der 
gleichgrosse, etwas schmälere 8-signatus, dieser hat aber auch viel breitere Augen, breiteren Rüssel, viel kürzeren und anders sculptirten Thorax, gekielte Schenkel und ganz andere Zeichnung.

Nachdem ich bereits einige wenige Exemplare der Art in früheren Jahren gefunden hatte (am 27. März, 8. April in cop.), gelang es mir im Spätherbste des vorigen Jahres dieselbe bei Theodosia in sehr grosser Menge zu finden, so dass mir zur Beschreibung nahe an 200 Exemplare vorlagen.

\section{Otiorrhynchus aurosquamulatus n. sp.}

Oblongo-ovatus, niger, nitidulus, squamulis oblongis aureis sat dense adspersus; rostro valido, punctato, subimpresso, in medio vel leviter carinato vel carina nulla; antennis robustis, funiculi articulo secundo primo vix duplo longiore, articulis 3, 4 oblongis, 5-7 rotundatis longitudine vix latioribus; prothorace longitudine latiore, fortiter granulato, dorso nudo in medio non canaliculato; lateribus rotundatis, dense squamulatis; elytris rugosis, punctatostriatis, interstitiis rugoso-granulatis, granulis poriferis; femoribus omnibus dente sat valido armatis, tibiis anticis arcuatis. Long. $10-11$, lat. $4 \mathrm{~mm}$.

Hab. Cauc. occid. (montes Circassiae).

Schwarz, etwas glänzend, ziemlich dicht goldbeschuppt, Kopf und Rüssel sind breit, fein runzlig, der letztere ist länger als der Kopf, oben schwach gefurcht mit einem bisweilen undeutlichen kurzen Kiele in der Mitte; Augen ziemlich stark vorragend; Fühler stark behaart, das zweite Geisselglied nicht ganz doppelt so lang als das erste, das dritte etwa dem ersten gleich, das vierte kürzer als das vorhergehende, die folgenden drei gerundet, kaum länger als breit, die Keule ziemlich lang oval. Halsschild wenig breiter als lang, an den Seiten stark gerundet, die grösste Breite vor der Mitte aufweisend, stark gekörnt, an den dicht goldbeschuppten Seiten sind die Körner weniger dicht gestellt als in der nackten Mitte, wo sie dichtgedrängt stehen und keine Mittellinie freilassen. Flügeldecken oval oder länglich oval $\left(1^{3} / \mathrm{s}^{-}\right.$bis $1 \frac{1}{2}$ mal so lang als breit), hinten etwas zugespitzt, gemeinschaftlich abgerundet, oben gewölbt mit länglich ovalen, goldgelben Schüppchen ziemlich dicht besetzt, ziemlich fein gestreift, die Zwischenräume er- 
haben, mit einer Reihe starker glänzender Körner; ausserdem finden sich jedoch Körner auch unregelmässig in den Streifen selbst; die Körnchen sind mit kurzen, anliegenden Härchen versehen. Unterseite durch kleinere Körnchen rugulös; die Schenkel sind alle ziemlich gleichstark und mit einem kurzen, aber deutlichen Zähnchen versehen; die Vorderschienen gebogen.

Diese hübsche Art gehört nach der Eintheilung Dr. Stierlin's in die 27. Rotte des Genus Otiorrhynchus, unterscheidet sich aber von allen Arten dieser Gruppe hinlänglich, um als besondere Art angesprochen zu werden. Schon auf den ersten Blick fällt sie durch die bedeutende Grösse und die röthlich goldene (nicht grüne) Beschuppung auf. Mit der einzigen bisher bekannten kaukasischen Art der Gruppe O. Tatarchani Reitt. ist sie nicht leicht zu verwechseln, da abgesehen von der Grösse und Beschuppung, die starken Fühlerglieder, die anders gebildeten Grlieder der Geissel, das Fehlen der Mittelfurche des Halsschildes, die behaarten Körner der Flügeldecken, die stärker gezähnten Schenkel und die gebogenen Vorderschienen aurosquamulatus genügend von Tatarchani unterscheiden.

Auf dem Berge Fischt im westlichen Kaukasus in zwei Exemplaren von Herrn Starck gefunden.

\section{Otiorrhynchus gibbicollis Boh.}

V. strongylus $\mathrm{n} .{ }^{*}$ ) Von gibbicollis unterschieden durch noch stärkere Rundung der Flügeldecken (Breite verhält sich zur Länge etwa wie $7: 8$ ), sowie dadurch, dass der Halsschild nicht längsrunzlig, sondern undeutlich runzlig-punktirt ist. Lg. 4- $\check{5}$, Br. $2-2.9 \mathrm{~mm}$.

K rim, auf kablen Bergen bei Guundshi und Buragan unter Steinen in grösserer Anzahl in der ersten Hälfte des Juli gesammelt.

V. Theodosianus $n$. In der Form gleicht diese Varietät vollkommen der Stammart (Flügeldeckenbreite verhält sich zur

*) Ot. strongylus Retows., wozu Theodosiamus als Varietät kommt, ist von gibbicollis durch hellere Färbung, kleineren, gedrungeneren Körper, der dichter behaart ist, und durch das viel längere erste Geisselglied der Fühler sicher specifisch verschieden.

E. Reitter. 
Länge derselben etwa wie $3: 4$ ), der Halsschild ist jedoch wie bei der vorigen Varietät und ausserdem sind die Hinterschenkel nur sehr schwach gezähnt, während bei gibbicollis typ. und v. strongylus alle Schenkel stark gezähnt sind. Ein weiterer, allerdings nur minutiöser Unterschied dürfte sein, dass die Schienen an der Einlenkungsstelle fast gerade sind, während sie bei der typischen Form und $v$. strongylus an dieser Stelle merklich gebogen sind. Lg. $4 \cdot 3-5.3, \mathrm{Br} .2-2.5 \mathrm{~mm}$.

Krim. Vereinzelt bei Theodosia vom Februar bis zum Mai und wieder vom August bis Mitte October. Auch bei Kertsch gefunden.

\section{Otiorrhynchus velutinus Germ.}

In den Bestimmungstabellen des Herrn Dr. Stierlin ist als Unterschied zwischen velutinus Germ. und exilis Boh. u. A. angegeben, dass die Naht bei velutinus hinten nicht vorragend sein soll; ich sammelte jedoch bei Kertsch Exemplare, bei denen die Naht hinten sehr deutlich hervortritt, im Uebrigen stimmen aber die Kertscher Exemplare ganz mit meinen an anderen Orten der Krim, sowie in Podolien gesammelten Exem. plaren von velutinus vollkommen überein (der Rüssel ist so lang wie der Kopf, das zweite Geisselglied der Fühler ist deutlich länger als das erste, die $Z_{w}$ wischenräume der Flügeldecken sind breit, sehr fein gekörnt), so dass sie jedenfalls zu velutinus gehören. Es fällt somit einer der Hauptunterschiede $\mathrm{zwischen}$ velutinus und exilis weg und ist es demnach vielleicht richtiger, letztere Species nur als Varietät von velutinus aufzufassen. Noch bemerke ich, dass die Pubescenz aller Krimer Exemplare von velutinus nicht so stark ist, als bei den mir vorliegenden Stücken aus Podolien und aus Wien.

\section{Otiorrhynchus caucasicus Stl.}

V. semigranulosus n. Unterscheidet sich von der Stammform dadurch, dass der Halsschild nur an den Seiten dicht gekörnt ist, die Mitte ist eben, ziemlich weitläufig punktirt.

West-Kaukasien, bei Novorossisk, wo auch die typische Form vorkommt. 


\section{$2 \mathrm{BHL}$ Biodiversity Heritage Library}

Retowski, O. 1887. "Neue Curculioniden aus der Krim und dem Kaukasus, nebst Bemerkungen über einige schon bekannte Arten." Wiener entomologische Zeitung 6, 130-134. https://doi.org/10.5962/bhl.part.17742.

View This Item Online: https://www.biodiversitylibrary.org/item/44060

DOI: https://doi.org/10.5962/bhl.part.17742

Permalink: https://www.biodiversitylibrary.org/partpdf/17742

\section{Holding Institution}

Smithsonian Libraries

\section{Sponsored by}

Smithsonian

\section{Copyright \& Reuse}

Copyright Status: NOT_IN_COPYRIGHT

This document was created from content at the Biodiversity Heritage Library, the world's largest open access digital library for biodiversity literature and archives. Visit BHL at https://www.biodiversitylibrary.org. 